\title{
Atienza Macías, Elena y Rodríguez Ayuso, Juan Francisco (directores). Las respuestas del Derecho a las crisis de Salud Pública. Dykinson, Madrid, 2020.
}

\author{
Ferdinando A. Insanguine Mingarro \\ Università degli Studi di Palermo
}

Fecha de recepción 01/10/2019 I De publicación: 15/06/2020

El objetivo principal de esta obra, dirigida por Elena Atienza Macías y Juan Francisco Rodríguez Ayuso y que cuenta con diecinueve contribuciones procedentes de muy diversas áreas de conocimiento jurídico, es brindar al lector un análisis pormenorizado de las principales implicaciones y consecuencias jurídicas que ha traído y seguirá trayendo consigo la crisis de Salud Pública ocasionada por el COVID-19.

La actualidad de la obra es innegable, recogiendo en cada uno de sus capítulos las más recientes novedades de la materia, a través de un detallado análisis de una gama muy amplia de documentos éticos y jurídicos. Como no podía ser de otra manera se analiza en profundidad el Real Decreto 463/2020 con el que se declara el estado de alarma y las prórrogas aprobadas el 27 de marzo y el 10 de abril. También son objeto de estudio las comunicaciones emitidas por la Organización Mundial de la Salud, los Documentos técnicos para profesionales y del Informe sobre los aspectos éticos en situaciones de pandemia coordinados por el Ministerio de Sanidad, las polémicas recomendaciones éticas para la toma de decisiones en la situación excepcional de crisis por pandemia COVID-19 en las unidades de cuidados intensivos propuestas por la Sociedad Española de Medicina Intensiva, Crítica y Unidades Coronarias (SEMICYUC) hasta llegar al Informe del Comité de Bioética de España sobre los aspectos bioéticos de la priorización de recursos sanitarios en el contexto de la crisis del coronavirus. Por lo tanto, el primer y evidente gran mérito de este libro consiste en su capacidad de estar al tanto de la frenética actualidad, consiguiendo elaborar una obra que aúna muchas de las implicaciones jurídicas que conlleva esta extraordinaria situación en un breve periodo de tiempo, lo que se manifiesta en un trabajo serio y exhaustivo pese a la proximidad de la facticidad analizada. Esta inmediatez de unos hecho inéditos proyecta a la doctrina jurídica hacia una función de concreta interpretación de la realidad, y no solo de especulación contemplativa: de hecho, lejos de ocuparse únicamente de aspectos 
teóricos, los autores proponen soluciones prácticas a los novedosos e impredecibles problemas planteados por la pandemia, impulsando así reflexiones que transitan - por utilizar la archiconocida y tal vez abusada expresión acuñada por Roscoe Pound en 1910 - del law in books al law in action. No solo políticamente, sino también académicamente los dilemas surgidos por esta crisis sanitaria global requieren de un enfoque multidisciplinario, puesto que las medidas operativas del declarado estado de alarma se extienden de forma capilar en todos los apartados de la vida, tocando así derechos y libertades muy diversas. Y es justamente el carácter multidisciplinario el segundo rasgo más reseñable de la obra, que no conoce fronteras disciplinarias ni temáticas, abarcando reflexiones de todas las ramas del Derecho hasta llegar a la orilla de la Bioética, con la contribución de Federico de Montalvo Jääskeläinen y Vicente Bellver Capella, respectivamente presidente y vocal del Comité de Bioética de España. Además, la obra no limita su horizonte al punto de vista de los académicos, sino que también se enriquece con la experiencia de los profesionales del Derecho: es el caso de Silvia Vilar González, Oficial de Notaria, que contribuye con un ensayo que pone de relieve la importante faceta que están cumpliendo en estos momentos los notarios ofreciendo servicios de urgencia.

Dicho enfoque poliédrico no ha implicado una renuncia a la autonomía funcional de cada rama del Derecho, ni un sacrificio en términos de nivel de detalle. De hecho, pese a la inmediatez de la situación sobre la que gravita el libro, la calamitosa situación de salud pública generada por el COVID19 y las respuestas que proporciona a ella el Derecho, podemos afirmar que de las contribuciones presentadas en la obra colectiva se predica la profundidad en el análisis, sacando así a relucir el tercer mérito del texto: una continua capacidad de percibir los matices de todas las consecuencias jurídicas, evaluando el contraste de las decisiones, en ocasiones contradictorias, que se tomaban en el escenario político, consiguiendo entrar en profundo detalle con argumentaciones jurídicas propias de cada área de conocimiento, sin perder de vista the big picture y poniendo en continua tensión y diálogo las diferentes disciplinas jurídicas. Esta dinámica brinda la posibilidad al lector de reflexionar sobre temas de fondo, que constituyen una llave hermenéutica privilegiada en una lectura político-jurídica de estos tiempos de pandemia. Uno de ellos es, sin duda alguna, la globalización que, relacionada con el COVID-19, asume la posición de problema y de solución al mismo tiempo. Como han señalado, entre otros, en sus contribuciones Vilar González y Cruz Ángeles, "la interconectividad globalizada de los sistemas de movilidad actuales" (p. 288), ha sido decisiva para la propagación del virus, puesto que la globalización ha proyectado a los Estados a una posición de interdependencia económica y social. Sin embargo, se apunta al mismo tiempo que esta crisis necesita de una respuesta global (de Montalvo 
Jääskeläinen - Bellver Capella, p. 245) a través de una coordinación entre los Estados, que deben plantearse renunciar a porciones de soberanía y autonomía (Cruz Ángeles, p. 293). Desgraciadamente, las primeras respuestas de la comunidad internacional y de la Unión Europea no parecen estar en esta línea. Como subraya Bombillar Sáenz en su ensayo con especial referencia a la UE, este ínfimo nivel de compromiso tendría incluso raíces normativas: en concreto, el desinterés político por una respuesta unitaria a nivel europeo estaría respaldado por el art. 168.5 TFUE que no prevé adecuados mecanismos de armonización de eventuales medidas adoptadas para luchar contra pandemias transfronterizas, poniendo en seria duda la misma esencia de la institución europea que parece unir "en la diversidad, pero no en la adversidad" (p. 65). El otro gran trait d'union es el concepto de vulnerabilidad, y no es casualidad que lo sea junto a la globalización, dado que este proceso económico-social ha expuesto a algunos grupos de individuos a una posición de debilidad que se ve ahora agrandada por los efectos de la pandemia. Citado más de cincuenta veces ${ }^{1}$ a lo largo de la publicación, al concepto de vulnerabilidad se recurre en prácticamente todas las contribuciones, poniendo de relieve que, ahora más que nunca, existe la necesidad jurídica y política de proteger a los individuos más débiles de nuestra sociedad.

El libro, por tanto, otorga al lector la posibilidad de tejer relaciones temáticas entre las diversas contribuciones, lo que reitera la idea de que el Derecho no debe afrontarse de forma fragmentada, sino que los diversos saberes del mundo jurídico guardan una estrecha relación e interconexión. Los diferentes enfoques contribuyen, así, a la profundización de los análisis jurídicos. De hecho, el orden con el que se suceden los ensayos no es casual: las primeras dos contribuciones, con la firma de Presno Linera y Sarrión Esteve, introducen al lector en el nuevo orden jurídico establecido por medio de los reales decretos. Sí, un nuevo orden porque como apunta Sarrión Esteve, la sistemática de decretos adoptada no se resuelve en una simple constatación del presupuesto de hecho que permite la declaración del estado de alarma, tratándose en realidad de un acto con carácter normativo que establece una nueva legalidad, constituyendo también fuente de habilitación de disposiciones y actos administrativos (p. 32). Por su parte, Presno Linera, a través de un brillante análisis técnico-jurídico del art. 116 CE y de la LO 4/1981, cuestiona si dicha nueva legalidad es efectivamente compatible con la institución del estado de alarma, que podría únicamente limitar los derechos fundamentales y no prohibirlos tout court, o se trataría de una condición que, fácticamente, se acerca mucho más a la forma

\footnotetext{
${ }^{1}$ Para calcular el número total de veces en que se cita al concepto de vulnerabilidad hemos computado las declinaciones terminológicas "vulnerable" (35), "vulnerabilidad" (11), "vulnerables" (5).
} 
jurídica del estado de excepción (pp. 25 y 26). Observando la producción normativa de los meses de marzo y abril, más que un nuevo orden, Palomar Olmeda detecta un desorden, puesto que "la crisis del COVID-19 se ha ido desenvolviendo en una maraña de normas de toda clase y condición" (p. 50) que abren dilemas sobre la jerarquía de las fuentes jurídicas. Entonces, para que en el futuro no se corra el riesgo de una deslegalización del ordenamiento jurídico (p. 57), el administrativista matiza la necesidad de formalizar "un marco de referencia en el que concretar la actuación administrativa y hacerlo con las características que exige la emergencia que trata de solucionar, pero sin convertir la emergencia en un elemento de contingencia sobre el conjunto de la norma" (p. 59). La obra sigue su paso moviéndose una vez más en el ámbito iuspublicista y específicamente administrativo, pero esta vez enfocándolo concretamente al servicio sanitario nacional. De hecho, en su contribución Bombillar Sáenz cuestiona la excesiva relevancia que la versión contemporánea del Estado de Bienestar otorga a la vertiente asistencial y a la dimensión individual, afirmando que la actual crisis sanitaria tendría que inducir a los poderes públicos a reorganizar el sistema sanitario poniendo en el centro a la salud pública (p. 76).

A partir del quinto capítulo, el libro empieza a ramificarse de forma capilar en todos los sectores del Derecho, empezando con el Derecho procesal. Con un análisis pormenorizado de las medidas más actuales, López Picó y Quesada López construyen un ensayo de gran utilidad para los profesionales de la justicia, procediendo a una sistematización del marco jurídico aplicable en términos de cómputo de plazos procesales, diferenciando de forma clara la jurisdicción civil, penal, social y administrativa contenciosa. De sumo interés resulta el examen, propuesto por Rodríguez Ayuso, acerca de los posibles efectos de la pandemia sobre el cumplimiento de la normativa en materia de protección de datos. A este respecto incluso en unas circunstancias tan excepcionales como las actuales, nunca se podría mermar, ni siquiera implícitamente, la normativa de origen europeo (p. 92), de modo que el autor evidencia como el Comité Europeo de Protección de Datos ha reconocido que "la normativa actual sobre protección de datos personales no impide tomar medidas en la lucha contra la pandemia" poniendo como único límite innegociable la protección del titular de los mismos (p. 94).

Los directores de la obra, conscientes del triste escenario económico que se viene anunciando desde hace semanas por efecto del lock-down global, han decidido dedicar a ello un núcleo de tres relevantes contribuciones. La primera, firmada por el italiano Massimo Cermelli y Aida Llamosas, ahonda en las políticas de Derecho laboral propuestas para proteger la situación del empleo nacional, 
profundizando con detenimiento y rigor en el instituto jurídico del ERTE por fuerza mayor y las nuevas y especiales medidas adoptadas para una flexibilización del proceso burocrático y administrativo. Con el ensayo de García Escobar, acerca de las cláusulas de refinanciación en contratos bancarios, se acompaña al lector hacia un necesario replanteamiento de los principios de Derecho bancario ínsitos en nuestro ordenamiento, que crean una situación de asimetría contractual cuyos efectos, en un periodo de excepcionalidad como el actual, podrían agrandarse poniendo en una posición de mayor vulnerabilidad al cliente bancario. De hecho, como apunta el autor, en nombre de una supuesta protección del principio de autonomía negocial, la actual normativa implica que las entidades financieras tengan, de facto, el control del contenido de dichas cláusulas, que se resuelven en una serie de facultades a favor únicamente de la parte fuerte. La tercera contribución que se mueve en la intersección entre Derecho y Economía nos la brindan Olivares Olivares y Sanchez-Archidona Hidalgo que, lejos de asumir únicamente una posición crítica, proponen "soluciones reales y prácticas en distintos impuestos que conforman nuestro sistema tributario" (p. 140) para construir una fiscalidad de excepción que garantice la liquidez necesaria. La posible extensión del umbral de vulnerables, por efecto de la crisis sanitaria y de sus implicaciones económicas, no puede dejar en la sombra la condición de grupos de individuos ya en fuerte dificultad antes del contagio masivo global. Entre ellos, sin duda alguna, se encuentran las personas con discapacidad y sus familias a los que Vivas Tesón dedica un apasionado y riguroso ensayo, en el que pone en evidencia "la injustificada desprotección institucional (tanto por acción como por omisión) de este colectivo" (p. 157) en necesidades tan básicas como la accesibilidad cognitiva de la información y de la comunicación sobre la emergencia sanitaria y dando eco a la preocupante exposición de niñas y mujeres con discapacidad a diferentes formas de violencia de género y abusos durante el confinamiento.

Tras un interesante trabajo sobre la crucial actividad de la notaría en esta crisis sanitaria, del que se ha ya hablado supra, la obra sigue con dos contribuciones enfocadas especialmente en el Derecho penal. En su elaborado ensayo, Armaza Armaza reflexiona sobre las consecuencias jurídicas en caso de quiebra de las medidas de confinamiento por personas infectadas, poniendo de relieve que los principios fundamentales de la ciencia penalista, como el principio de legalidad y la prohibición de analogía in malam partem, convierten en ilegal, en el marco jurídico actual, cualquier pretensión sancionadora penal de conductas de quebrantamiento de orden de confinamiento, dejando así desprotegido el bien jurídico fundamental de la salud pública. Por otra parte, y siempre en una perspectiva penal, Gálvez Jiménez afronta el tema de la celebración de actos multitudinarios en tiempo 
de pandemia, que tiene como telón de fondo el riesgo de futuros contagios y, por consiguiente, la generación de rebrotes de la enfermedad.

Los dos siguientes ensayos analizan, desde el punto de vista del Derecho biomédico y de la Bioética, las tragic choices en las operaciones de triaje para el acceso a recursos sanitarios escasos durante las semanas de pico de la pandemia, cuando no había respiradores y plazas en Unidades de Cuidado Intensivo (UCI) suficientes. Concretamente, en la primera contribución, De Miguel Beriain enfatiza cómo el marco jurídico aplicable constituiría, desgraciadamente, una traba importante para el desarrollo de una política sanitaria realmente orientada al objetivo de salvar el mayor número de vidas posibles, puesto que la primacía del derecho individual a la salud sobre el interés colectivo de la ciencia y la sociedad en su conjunto constituye una base jurídica incompatible con la posibilidad de reasignación de recursos que permitiría maximizar el número de vidas salvadas. Después de un análisis introductorio sobre la vasta gama de cuestiones bioéticas que surgen en tiempos de pandemia, de Montalvo Jääskeläinen y Bellver Capella deciden dedicar también gran parte de su investigación a los criterios de priorización en el acceso a los recursos escasos, tomando como referencia el reciente informe al respecto del Comité de Bioética de España y combinando de forma eficaz argumentos bioéticos y argumentos marcadamente jurídicos. Con una fuerte crítica al concepto de valor social de la persona introducido por las recomendaciones éticas de la SEMICYUC, los autores, apoyándose también en la bioética comparada, desestructuran la tesis utilitarista subyacente a los criterios propuestos por la citada sociedad por su incompatibilidad con el principio de la dignidad humana y la rationale universal de los derechos humanos, cuestionando además la legitimidad formal de recomendaciones emitidas por sociedades científicas. Partiendo del análisis del art. 43.2 CE, los autores concluyen que "el carácter expansivo de la actividad científica y tecnológica no puede ir en detrimento del carácter jurídico-político de la toma de decisiones por parte de las autoridades públicas” (p. 256).

Carmen Pérez González y Jonatán Cruz Ángeles firman las dos siguientes contribuciones que se mueven en la perspectiva del Derecho internacional público. En el primer ensayo se investiga sobre las herramientas existentes en el Derecho internacional de los derechos humanos en el ámbito de la lucha contra las pandemias, donde, para cumplir con la necesidad de proteger a los seres humanos más vulnerables, cobra gran importancia el concepto de seguridad humana, en su versión hermenéutica más amplia. Por su parte, Cruz Ángeles reflexiona, entre otras cosas, sobre el más clásico de los temas de Derecho internacional público, es decir la posición jurídica del estado en el ordenamiento internacional, 
apuntando que para combatir el COVID-19 es necesario reforzar la coordinación entre ellos y con otros actores internacionales, además de superar un concepto estático de soberanía nacional.

El siguiente ensayo vuelve con fuerza al corazón del derecho doméstico, referenciando de forma directa la carta constitucional. Así introduce al lector hacia la reflexión sobre el tema candente de las restricciones de derechos fundamentales que se están produciendo durante el estado de alarma, dado que esta pandemia ha traído consigo un cambio en la estructura de los derechos humanos y fundamentales, cuestionando la naturaleza insuperable del carácter prima facie de los mismos. En concreto, con un enfoque didáctico y pedagógico, Pérez Álvarez razona sobre las limitaciones a la libertad religiosa, poniendo de relieve las diferencias entre el disfrute de los derechos derivados por dicha libertad antes y después del endurecimiento de las medidas de confinamiento. Cierra la obra el ensayo de Atienza Macías que pasa revista a las múltiples incidencias que la pandemia ha tenido en el mundo del deporte, con un especial enfoque a las consecuencias jurídicas y económicas, sensibilizando al lector, entre otras cosas, sobre la trascendencia de los e-Sports, que pueden constituir una fundamental válvula de escape para el futuro del deporte.

Después de un largo viaje entre las implicaciones jurídicas del COVID-19, el lector sale concienciado sobre cuáles han sido las respuestas del Derecho a esta importante crisis sanitaria y, sobre todo, cuáles habrían podido ser y podrían ser las herramientas adecuadas para minimizar los impactos sociales y económicos, en particular hacia los grupos más vulnerables de nuestra sociedad.

En definitiva, la obra Las respuestas del Derecho a las crisis de Salud Pública se propone como instrumento indispensable tanto para la reflexión académica y teórica como para los operadores jurídicos, que podrán encontrar en ella útiles herramientas para su actividad cotidiana. 